\title{
Efavirenz-based simplification after successful early lopinavir-boosted-ritonavir- based therapy in HIV-infected children in Burkina Faso and Côte d'Ivoire: the MONOD ANRS 12206 non-inferiority randomised trial
}

Désiré Lucien Dahourou ${ }^{1,2,3}$, Madeleine Amorissani-Folquet ${ }^{4}$, Karen Malateste $^{3}$, Clarisse Amani-Bosse $^{5}$, Malik Coulibaly ${ }^{1}$, Carole Seguin-Devaux ${ }^{6}$, Thomas Toni ${ }^{7}$, Rasmata Ouédraogo ${ }^{8}$, Stéphane Blanche ${ }^{9,10}$, Caroline Yonaba $^{11}$, François Eboua ${ }^{12}$, Philippe Lepage ${ }^{13}$, Divine Avit ${ }^{5}$, Sylvie Ouédraogo ${ }^{14}$, Philippe Van de Perre ${ }^{15,16}$, Sylvie N'Gbeche ${ }^{17}$, Angèle Kalmogho ${ }^{11}$, Roger Salamon ${ }^{3}$, Nicolas Meda ${ }^{2,18}$, Marguerite Timité-Konan ${ }^{12}$, Valériane Leroy ${ }^{19^{*}}$, on behalf of the MONOD Study Group

\begin{abstract}
Background: The 2016 World Health Organization guidelines recommend all children $<3$ years start antiretroviral therapy (ART) on protease inhibitor-based regimens. But lopinavir/ritonavir (LPV/r) syrup has many challenges in low-income countries, including limited availability, requires refrigeration, interactions with anti-tuberculous drugs, twice-daily dosing, poor palatability in young children, and higher cost than non-nucleoside reverse transcriptase inhibitor (NNRTI) drugs. Successfully initiating LPV/r-based ART in HIV-infected children aged $<2$ years raises operational challenges that could be simplified by switching to a protease inhibitor-sparing therapy based on efavirenz (EFV), although, to date, EFV is not recommended in children $<3$ years.

Methods: The MONOD ANRS 12026 study is a phase 3 non-inferiority open-label randomised clinical trial conducted in Abidjan, Côte d'Ivoire, and Ouagadougou, Burkina Faso (ClinicalTrial.gov registry: NCT01127204). HIV-1-infected children who were tuberculosis-free and treated before the age of 2 years with 12-15 months of suppressive twice-daily LPV/r-based ART (HIV-1 RNA viral load (VL) $<500$ copies/mL, confirmed) were randomised to two arms: once-daily combination of abacavir (ABC) + lamivudine (3TC) + EFV (referred to as EFV) versus continuation of the twice-daily combination zidovudine (ZDV) or ABC + 3TC + LPV/r (referred to as LPV). The primary endpoint was the difference in the proportion of children with virological suppression by 12 months post-randomisation between arms (14\% non-inferiority bound, Chi-squared test).

(Continued on next page)
\end{abstract}

\footnotetext{
* Correspondence: valeriane.leroy@inserm.fr

${ }^{19}$ Inserm, Unité U1027, Université Toulouse 3, Toulouse, France

Full list of author information is available at the end of the article
} 
(Continued from previous page)

Results: Between May 2011 and January 2013, 156 children (median age 13.7 months) were initiated on ART. After 12-15 months on ART, 106 (68\%) were randomised to one of the two treatment arms (54 LPV, 52 EFV); 97 (91\%) were aged <3 years. At 12 months post-randomisation, 46 children (85.2\%) from LPV versus 43 (82.7\%) from EFV showed virological suppression (defined as a $V L<500$ copies $/ \mathrm{mL}$; difference, 2.5\%; $95 \%$ confidence interval $(\mathrm{Cl}),-11.5$ to 16.5$)$, whereas seven (13\%) in LPV and seven (13.5\%) in EFV were classed as having virological failure (secondary outcome, defined as a $V L \geq 1000$ copies $/ \mathrm{mL}$; difference, $0.5 \% ; 95 \% \mathrm{Cl},-13.4$ to 12.4). No significant differences in adverse events were observed, with two adverse events in LPV (3.7\%) versus four (7.7\%) in EFV ( $p=0.43)$. On genotyping, 13 out of 14 children with virological failure (six out of seven EFV, seven out of seven LPV) had a drugresistance mutation: nine (five out of six EFV, four out of seven LPV) had one or more major NNRTI-resistance mutations whereas none had an LPV/r-resistance mutation.

Conclusions: At the VL threshold of 500 copies $/ \mathrm{mL}$, we could not conclusively demonstrate the non-inferiority of EFV on viral suppression compared to LPV because of low statistical power. However, non-inferiority was confirmed for a VL threshold of $<1000$ copies $/ \mathrm{mL}$. Resistance analyses highlighted a high frequency of NNRTI-resistance mutations. A switch to an EFV-based regimen as a simplification strategy around the age of 3 years needs to be closely monitored.

Trial registration: ClinicalTrial.gov registry nNCT01127204, 19 May 2010.

Keywords: Africa, HIV, Early antiretroviral treatment, Infants, Protease inhibitors, Lopinavir, Efavirenz, Randomised clinical trial, Virological outcomes, Treatment simplification

\section{Background}

Despite effective interventions to prevent mother-tochild transmission (PMTCT) in sub-Saharan Africa [1], the seriousness of the paediatric epidemic remains real, mainly for operational reasons. According to UNAIDS, in 2013, 3.2 million children $<15$ years of age were living with HIV and 240,000 children were newly HIV-infected worldwide [2]. In the absence of antiretroviral therapy (ART), HIV-related infant mortality in Africa is dramatically high and occurs early, reaching $52 \%$ by the age of 2 years [3]. The 12-month efficacy of early ART initiated in all HIV-infected children reported in the CHER trial in South Africa showed a significant reduction of $76 \%$ in infant mortality among children treated immediately from 12 weeks of age, compared to those deferred according to the 2006 World Health Organization (WHO) recommendations [4]. Consequently, ART initiation was recommended for all HIV-infected children $<12$ months of age in 2008 [5], extended to all children $<24$ months in 2010 [6], and at the earliest convenience in all those $<5$ years in 2013 [7]. In 2015, WHO recommended that ART be initiated in everyone living with HIV at any CD4 cell count [8].

In low-income countries, the first-line therapy recommended for all children $<36$ months is based on a boosted protease inhibitor, lopinavir-boosted ritonavir $(\mathrm{LPV} / \mathrm{r})$, regardless of perinatal non-nucleoside reverse transcriptase inhibitor (NNRTI) exposure [7, 8]. Two trials have demonstrated the superiority of first-line LPV/rbased ART compared to first-line nevirapine (NVP) in populations of young children with or without preexposure to NVP for PMTCT $[9,10]$. LPV/r is a potent drug, with a high genetic barrier against resistance, and is especially effective when combined with two nucleoside reverse transcriptase inhibitors (NRTIs) [11]. First-line LPV/r also leads to longer life expectancy and is cost saving compared to first-line NVP [12]. The backbone recommended is based on two NRTIs: abacavir (ABC), preferentially, or zidovudine (AZT), and lamivudine (3TC).

The choice of LPV/r-based therapy may nevertheless be operationally challenging, with many drawbacks restraining its use as a first-choice therapy in young children in Africa. The currently available oral syrup forms of $\mathrm{LPV} / \mathrm{r}$ for infants have a thermostability issue that requires the use of refrigeration for storage and distribution [13], as well as having poor palatability. LPV/r is also used as a second-line drug owing to the current scarcity of antiretroviral drugs adapted to paediatric use. In addition, there are potential metabolic complications and interactions with anti-tuberculous drugs [14]. In May 2015, the United State Food and Drug Administration (FDA) approved the use of $\mathrm{LPV} / \mathrm{r}$ oral pellets in children (http://www.accessdata.fda.gov/drugsatfda_docs/appletter/ 2015/205425Orig1s000TAltr.pdf), which has overcome the challenges of the cold chain. However, these pellets still need to be assessed in Africa. Consequently, we explored whether it would be possible to substitute this initial LPV-based regimen in children with confirmed virological suppression with a once-daily ART that is easier to handle and more acceptable, while saving protease inhibitors for later use if virological failure occurs, in the context of poor access to second-line treatments. We selected efavirenz (EFV) dosed once daily with paediatric-friendly formulations, which is 
well tolerated and can be used in combination with anti-tuberculous drugs [15].

We hypothesised that, for children who were started on a twice-daily LPV-based ART and who were virologically suppressed after an initial 12-15-month period, ART could be simplified in the long term with a oncedaily EFV-based therapy.

\section{Methods}

\section{Study design}

The MONOD ANRS 12206 study is a non-inferiority, open-label phase 3 randomised clinical trial conducted in Ouagadougou, Burkina Faso, and Abidjan, Côte d'Ivoire (ClinicalTrial.gov registry number: NCT01127204, first registered on 19 May 2010). Study sites were the AboboAvocatier urban health clinic, the CePReF-enfant and the Yopougon and Cocody University Hospitals in Abidjan, and the Yalgado Ouédraogo and the Charles de Gaulle University Hospitals in Ouagadougou. The protocol was approved by the Comité d'Ethique pour la Recherche en Santé du Burkina Faso and the Comité National d'Ethique et de la Recherche en Côte d'Ivoire.

\section{Participants}

An initial therapeutic cohort included all children with an HIV-1 infection confirmed by HIV-1 DNA polymerase chain reaction (PCR) who were aged $<24$ months, free of tuberculosis, and antiretroviral-naïve except for exposure to PMTCT interventions. Both parents had to provide written consent. This initial cohort received 1215 months of treatment with two NRTIs (ABC or AZT and 3TC) and LPV/r given twice daily, together with prophylaxis against opportunistic infections with cotrimoxazole and therapeutic education. Exclusion criteria were age $\geq 24$ months; on current ART; a known intolerance to at least one of the drugs; HIV-2-infected or HIV-1 and -2 co-infected; tuberculosis; or a haemoglobin level $<7 \mathrm{~g} / \mathrm{dL}$, neutrophils $\leq 750 / \mathrm{mm}^{3}$, creatinine $\geq 5 \times$ normal range, or aspartate transaminase (AST) or alanine transaminase (ALT) $\geq 5 \times$ normal range. After the initial cohort period, children with an undetectable HIV1 RNA viral load (VL) $<500$ copies/mL at 12 months (confirmed at a 3-month interval) were randomised to either switch to once-daily ABC + 3TC + EFV (hereafter referred to as EFV) therapy or stay on the twice-daily $\mathrm{LPV}$ regimen $(\mathrm{AZT}+3 \mathrm{TC}+\mathrm{LPV} / \mathrm{r}$ or $\mathrm{ABC}+3 \mathrm{TC}+$ $\mathrm{LPV} / \mathrm{r})$. Children with a detectable VL were not randomised and were maintained on a LPV regimen with therapeutic education reinforcement.

\section{Randomisation}

A centralised computer-generated sequentially numbered block randomisation list, stratified according to country, was drawn up and included in an online software randomisation system to allocate the treatment arm through a secure website set up by the data management centre in Bordeaux, France. After the programme verified all pre-specified inclusion criteria, children were automatically randomly assigned to one arm (1:1), either the control strategy (LPV-based therapy) the simplified strategy (EFV-based therapy). After randomisation, an automatic printout showing the treatment decision and the ID number of the randomised arm was forwarded to the trial coordinator.

\section{Trial treatments}

In the control strategy, children received twice-daily triple therapy: (ZDV) (syrup $10 \mathrm{mg} / \mathrm{mL}, 4 \mathrm{mg} / \mathrm{kg}$ every 12 hours) or $\mathrm{ABC}$ (syrup $20 \mathrm{mg} / \mathrm{mL}, 8 \mathrm{mg} / \mathrm{kg}$ every 12 hours) + 3TC (syrup $10 \mathrm{mg} / \mathrm{mL}, 4 \mathrm{mg} / \mathrm{kg}$ every 12 hours) + LPV/r (syrup 80/20 mg/mL, $12 \mathrm{mg} / \mathrm{kg}$ every 12 hours). In the simplified strategy, children received once-daily triple therapy: $\mathrm{ABC}$ (syrup $20 \mathrm{mg} / \mathrm{mL}, 16 \mathrm{mg} /$ $\mathrm{kg}$ every morning) +3TC (syrup $10 \mathrm{mg} / \mathrm{mL}, 8 \mathrm{mg} / \mathrm{kg}$ every morning) + EFV (syrup $30 \mathrm{mg} / \mathrm{mL}, 25 \mathrm{mg} / \mathrm{kg}$ every morning on an empty stomach). Although EFV is not recommended for children $<3$ years or $<10 \mathrm{~kg}$, according to the WHO guidelines [7], we used EFV in children younger than the recommended age and at a dosage of $25 \mathrm{mg} / \mathrm{kg}$, according to a paediatric pharmacokinetic (PK) study conducted in Burkina Faso [16]. As recommended by the WHO, all children systematically received prophylaxis for opportunistic infections with cotrimoxazole syrup: sulfamethoxazole $(20 \mathrm{mg} / \mathrm{kg})+$ trimethoprim $(4 \mathrm{mg} / \mathrm{kg})$ once daily during the entire study. The assistant pharmacist and social worker systematically delivered therapeutic education when the drugs were given to families.

The drugs were provided by the national AIDS programmes under the responsibility of the country coordinating centres in charge of supplies and qualification of the batches. The inclusion process in the initial cohort started in May 2011. In 2012, in Abidjan, the national AIDS control programme introduced oro-dispersible fixed-dose formulation tablets for $\mathrm{ABC}$ and $3 \mathrm{TC}$ using WHO weight band dosing to substitute for the syrup formulations.

\section{Procedures}

A pre-inclusion visit, 4 weeks before ART initiation, included informed consent, an interview to assess medical history (perinatal or neonatal PMTCT exposure), a complete clinical examination (weight, height and WHO clinical staging), tuberculosis screening (chest X-ray), a standard blood test (haematology, creatinine, urea, AST, ALT, total bilirubin, glucose, alkaline phosphatases, amylase, lipase, lipid assessment [total cholesterol, triglycerides, low-density lipoprotein, high-density 
lipoprotein, very low-density lipoprotein], fasting blood glucose), a CD4 lymphocyte sub-population count (percentage and absolute count), and a confirmation of HIV status (quantitative HIV-1 RNA in plasma and quantitative proviral DNA). Where symptoms suggested tuberculosis (prolonged fever, chronic cough, recent malnutrition or failure of classic antibiotics for an infectious syndrome) the diagnosis was completed with a tuberculin skin test, gastric lavage on three consecutive days and stool examination for Mycobacterium tuberculosis.

All children were followed for 12-15 months after inclusion (defined as ART initiation), then for 12 months after randomisation. After inclusion, children had monthly clinical follow-up visits recording all clinical events, including adverse effects, weight- and height-forage z-scores calculated using the WHO software, drug uptake, measurement of adherence (doses taken in the past 4 days), delivery of drugs and therapeutic education. Screening for clinical neurological/sleep adverse events was performed at each monthly visit by trained paediatricians who systematically looked for sleeping adverse events and performed a neurological examination.

Standard blood tests were repeated every 6 months. CD4 cell counts and VL were measured quarterly at the Laboratoire du CeDreS in Abidjan and the Reference Laboratory of CHU Charles de Gaulle in Ouagadougou using a FACScan flow cytometer (Becton Dickinson, Mountain View, CA). VLs were measured with real-time PCR using a commercial assay (Generic HIV Charge Virale, Biocentric, Bandol, France) [17]. These methods were being used at that time according to the manufacturer's protocol in both Abidjan and Ouagadougou, where this method was validated. At the time of study implementation, in 2011, the manufacturer's threshold for VL was 400 copies $/ \mathrm{mL}$ as written in the protocol, but the threshold validated at the country level differed: it was 400 copies $/ \mathrm{mL}$ in the Abidjan laboratory and 500 copies/mL in the Ouagadougou laboratory. The laboratory in Ouagadougou was not able to guarantee results below 500 copies $/ \mathrm{mL}$. Therefore, we decided to homogenise the threshold to $<500$ copies $/ \mathrm{mL}$ at both sites to define viral suppression. HIV-1 genotypic resistance testing was performed upon virological failure (HIV-1 RNA $\geq 1000$ copies $/ \mathrm{mL}$, the commonly used threshold to guide treatment strategies [8]) and at enrolment before ART initiation in Abidjan for samples collected in Côte d'Ivoire and in Luxembourg for samples collected in Burkina Faso. The ANRS consensus technique (www.hiv frenchresistance.org) was used to genotype protease and reverse transcriptase genes. Sequences were edited with Bio-Edit sequence Alignment Editor (version 7.0) and trees constructed with Mega 4. Relevant drug-resistance mutations were interpreted according to the Stanford University HIV Drug Resistance Database (HIVdb Program, http://hivdb.stanford.edu) and the ANRS-v24 interpretation rule (http://www.hivfrenchresistance.org/2011/Algo2011.pdf). HIV-1 subtypes were assigned using REGA (http://www.bioafrica.net/rega-genotype/html/index.html) and COMET (http://comet.retrovirology.lu) HIV-1 subtyping tools against reference HIV-1 group $M$ sequences from GenBank (http://www.ncbi.nlm.nih.gov/Genbank/ index.html). Blood samples were collected from children and transferred for processing within 4 hours. Two plasma samples were prepared and stored at $-80{ }^{\circ} \mathrm{C}$ : one to perform VL measurement and one for resistance testing if the VL was $>1000$ copies $/ \mathrm{mL}$. Quality controls were performed for diagnostic PCR and VL (CDC, Atlanta, GA, USA) every 6 months and for genotyping (ANRS, Paris, France or Quality Controls in Molecular Diagnostics, Utrecht, the Netherlands) on a yearly basis.

\section{Outcomes}

The primary outcome was the proportion of children alive and with virological suppression (defined as HIV-1 RNA $<500$ copies $/ \mathrm{mL}$ ) at 12 months post-randomisation; this specific time point was considered regardless of any detectable VL between randomisation and 12 months. Secondary outcomes were virological failure (defined as HIV-1 RNA $\geq 1000$ copies/mL, the commonly used threshold to guide treatment strategies [8]) at 12 months postrandomisation, adverse events, resistance mutation profiles, the clinical-immunological response, the pharmacokinetic parameters, adherence, and cost.

\section{Statistical analysis}

For a non-inferiority trial, the statistical parameter of interest is the difference in successful viral suppression rate 12 months after the switch, defined in this instance as the rate of viral suppression in the LPV arm (control) minus the rate in the EFV arm, using a Chi-squared test. If this difference is $>0$, outcomes favour the control group [18]. We aimed to obtain virological success of at least $76 \%$ at 12 months post-switch. We pre-specified that a margin of $<14 \%$ for the $95 \%$ confidence interval (CI) of the difference in the primary outcome between the two arms would meet our criteria for non-inferiority. Both an intention-to-treat analysis conducted using all available data, and a per-protocol analysis were conducted as recommended for non-inferiority trials [19]. Based on our anticipated enrolment of 146 children with 73 children per arm, we expected an $80 \%$ power to detect this difference. In the CHER trial, the 12-month survival probability in infants on a $\mathrm{LPV} / \mathrm{r}$-based triple therapy was $96 \%$ [4]. Because virological data were not yet available at the time of our protocol, we expected a 95\% response on LPV according to the Yeni 2008 report [11]. Thus, assuming a 12-month virological suppression among survivors on LPV of 90\%, we anticipated 
recruited 162 children in the initial LPV-based cohort. To compare the characteristics of the study population, we used Chi-squared or Fisher's exact tests for categorical variable and $t$ tests or Mann-Whitney tests for continuous variables. We analysed the correlates of viral suppression at 12 months post-randomisation, using a multivariate logistic regression. All $p$ values were two sided and $p<0.05$ was considered statistically significant. Analyses were performed using SAS version 9.1.3.

\section{Results}

\section{Trial profile and baseline characteristics}

Between May 2011 and January 2013, 226 children were referred to the study clinics (Fig. 1). Of these, 65 children $(28 \%)$ were not initiated on ART, mainly due to parent's refusal (12\%), early deaths (10\%), a false-positive dried blood spot HIV DNA PCR result (4\%) or other reasons $(2 \%)$. That left 161 children $(72 \%)$ who were initiated on ART before 24 months of age [20]. Among them, five were initiated on EFV-based ART because of tuberculosis co-infection at inclusion.

The remaining 156 children were initiated on LPVbased ART (Fig. 1). Their median age at HIV-1 diagnosis was 8.5 months, and at ART initiation was 13.7 months. After 12-15 months on ART, only $68 \%$ were alive and showed virological suppression: 13 had died (8\%), two were lost to follow-up (1\%), three withdrew (2\%) and 32 had virological failure (21\%). Details on this cohort are presented elsewhere [21].

Of the 106 children who were eligible for randomisation, that is, alive and showing virological suppression, 54 were randomised to maintain LPV therapy, and 52 to

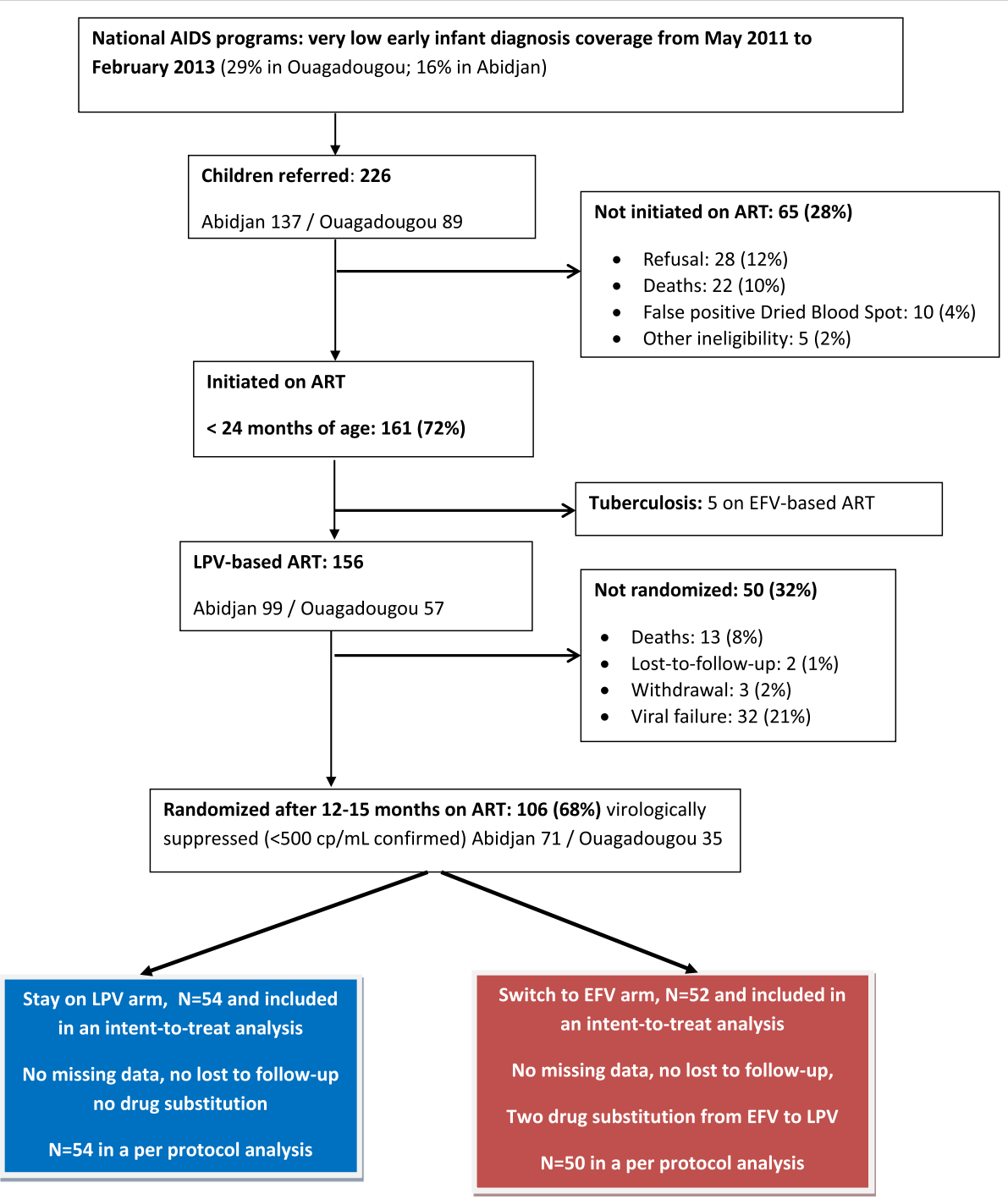

Fig. 1 MONOD ANRS 12206 Trial profile in Abidjan, Côte d'Ivoire, and Ouagadougou, Burkina Faso, 2011-2015. ART antiretroviral therapy, EFV efavirenz-based ART, LPV lopinavir-boosted-based ART 
switch to EFV (Fig. 1); all were included in the intentionto-treat analysis. Among the children randomised, 91\% (97 out of 106) were aged $<3$ years ( 49 in the LPV arm and 48 in the EFV arm).

There were no significant differences between the two groups' baseline characteristics at the time of randomisation (Table 1). Overall, 67.0\% lived in Abidjan, $55.7 \%$ were girls, the father was the main caregiver for $17.0 \%, 39.6 \%$ had not been exposed to any PMTCT intervention or maternal ART, $30.2 \%$ were exposed to perinatal PMTCT prophylaxis alone, $8.5 \%$ were born to mothers on ART, and $21.7 \%$ were exposed to postnatal maternal ART initiated during breastfeeding (Table 1). At the time of ART initiation, the children already had advanced HIV-disease progression: $54.7 \%$ were WHO stage 3 or 4 [6], the median CD4 percentage was $20.8 \%$ and their mean VL was $6.1 \log 10$ copies/mL (SD: 1). After 12-15 months on ART, at the time of randomisation, the median age was 26.8 months and median CD4\% had increased to 35.9\%; the CD4\% for both groups was within the normal range. Overall, children were virologically suppressed for a median of 6 months before randomisation.

\section{Virological suppression}

At 12 months post-randomisation, all children were alive and followed up, without any missing data on VL outcomes (Table 2). In an intention-to-treat analysis, 46 out of 54 children $(85.2 \%)$ in the LPV arm vs. 43 out of 52 $(82.7 \%)$ in the EFV arm had a VL $<500$ copies $/ \mathrm{mL}(p=$ 0.72). The difference was $2.5 \%$ (95\% CI, -11.5 to 16.5$)$, tending to favour the LPV arm. The 95\% CI included the pre-specified non-inferiority margin of $14 \%$; therefore, this analysis was deemed inconclusive. The actual statistical power to detect a difference was $67 \%$. Among the children aged $<3$ years, 42 out of $49(85.7 \%)$ in the LPV arm vs. 39 out of $48(81.3 \%)$ in the EFV arm had a VL $<500$ copies/mL $(p=0.55)$.

With regards our secondary outcome of virological failure using the threshold of $>1000$ copies $/ \mathrm{mL}$, in the intention-to-treat analysis, 7 out of 54 children (13.0\%) in the LPV arm failed vs. 7 out of $52(13.5 \%)$ in the EFV arm $(p=0.59)$. The difference between these rates was $-0.5 \%$ (95\% CI, -13.4 to 12.4 ). The $95 \%$ CI does not include the pre-specified non-inferiority margin of $14 \%$; therefore, at the 1000 copies $/ \mathrm{mL}$ threshold, EFV was considered non-inferior to LPV in our trial.

There were no significant differences in children's characteristics according to virological success (Tables 3 and 4). For the 17 children who failed to show virological suppression ( $\geq 500$ copies $/ \mathrm{mL}$ ) at 12 months, 10 failures occurred within the first 6 months. Drug modifications occurred in two children, who were switched from EFV to LPV: one for sleeping disorders persisting 10 months after randomisation, and one for hyper-transaminasaemia due to a cytotoxic treatment administrated by a healer (Table 5). The sensitivity per-protocol analysis gave similar results compared to the intention-to-treat analysis: 46 children (85.2\%) in the LPV arm vs. $42(84.0 \%)$ in the EFV arm had a VL $<500$ copies $/ \mathrm{mL}$, a difference of $1.2 \%$ (95\% CI, -12.7 to 15.1$)$. Using the 1000 copies $/ \mathrm{mL}$ threshold, seven children (13.0\%) in the LPV arm showed virological suppression vs. six (12.0\%) in the EFV arm, with a difference of one (95\% CI, -11.7 to 13.7$)$.

\section{Other secondary outcomes}

After 12 months, $53.8 \%$ of children overall were nonimmunodeficient, and there were no significant differences in $\mathrm{CD} 4 \%$ between arms: the median $\mathrm{CD} 4 \%$ was $37.3 \%$ in the LPV arm vs. $37.1 \%$ in the EFV arm $(p=$ 0.85 ; Table 2). Children in the LPV arm had a 0.1 lower mean z-score for weight-for-age, height-for-age and weight-for-height, although this difference was not significant between arms. There were no significant differences in the occurrence of severe adverse events after randomisation (Table 5): two hospitalisations occurred in the LPV arm vs. four in the EFV arm, all due to infectious diseases $(p=0.43)$. One grade 4 adverse event occurred in the EFV arm, with hepatitis due to cytotoxic treatment administered by a healer, but this was not judged as antiretroviral-related. There were no significant differences in day-time or night-time sleeping disorders declared by caregivers between the arms, with four in the LPV arm vs. five in the EFV arm, though one child in the EFV arm did have persistent day-time and nighttime sleeping disorders leading to a treatment substitution to LPV after 10 months. No clinical seizures were reported. There was no difference in the number of higher grade (grade 3 or 4) biological adverse events between the EFV and LPV arms, although we noted a significantly higher rate of neutropenia in the LPV arm, often associated with ZDV $(p=0.02)$.

\section{Drug-resistance profiles}

At 12 months post-randomisation, 13 out of 14 children with plasma HIV-1 RNA >1000 copies/ml underwent viral resistance genotyping (one viral sequence could not be amplified). Of these 13 children who showed virological failure, $10(77 \%)$ showed at least one major drugresistance mutation, mainly against NNRTIs (9 out of 13 ; 69\%) or against NRTIs (6 out of 13; 46\%) (Table 6). NNRTI-resistance mutations were mainly K103N and Y181C; NRTI-resistance mutations were primarily against 3TC (M184V). Four children with NNRTIresistant viruses exhibited cross-resistance to secondgeneration NNRTI treatment with etravirine and rilpivirine. No protease inhibitor resistance was detected. In 
Table 1 Baseline characteristics according to randomisation arm of the $106 \mathrm{HIV}$-1-infected children randomised in the ANRS 12206 MONOD trial (Abidjan and Ouagadougou, May 2011-April 2014)

\begin{tabular}{|c|c|c|c|c|}
\hline Characteristics & Total $N=106$ & $\begin{array}{l}\text { AZT or } A B C+3 T C+L P V / r \\
\text { (twice daily) } N=54\end{array}$ & $\begin{array}{l}\mathrm{ABC}+3 \mathrm{TC}+\mathrm{EFV} \\
\text { (once daily) } \mathrm{N}=52\end{array}$ & $p$ value \\
\hline \multicolumn{5}{|l|}{ Pre-trial characteristics } \\
\hline Abidjan site, n (\%) & $71(67.0)$ & $36(66.7)$ & $35(67.3)$ & 0.94 \\
\hline Age (months) at HIV-1 diagnosis, median (IQR) & $8.5(3.3-15.6)$ & $8.4(3.8-16.5)$ & $9.8(2.8-15.4)$ & 0.84 \\
\hline Age (months) at ART initiation, median (IQR) & $13.7(7.9-18.4)$ & $12.8(8.1-18.4)$ & $14.2(7.6-18.4)$ & 0.96 \\
\hline Female, n (\%) & $59(55.7)$ & $35(64.8)$ & $24(46.2)$ & 0.05 \\
\hline Father or other as main caregiver, $\mathrm{n}(\%)$ & $18(17.0)$ & $10(18.5)$ & $8(15.4)$ & 0.67 \\
\hline Tap water at home, n (\%) & $78(73.6)$ & $39(72.2)$ & $39(75.0)$ & 0.74 \\
\hline Electricity at home, $\mathrm{n}(\%)$ & $84(79.2)$ & $43(79.6)$ & $41(78.9)$ & 0.92 \\
\hline Ever breastfed from birth, $\mathrm{n}(\%)$ & $92(86.8)$ & $45(83.3)$ & $47(90.4)$ & 0.28 \\
\hline Breastfeeding duration (months) for those breastfed, median (IQR) & $13.8(7.6-21.4)$ & $16.0(7.5-21.5)$ & $12.0(7.7-19.6)$ & 0.49 \\
\hline \multicolumn{5}{|l|}{ History of antiretroviral drug exposure } \\
\hline Prenatal maternal ART, n (\%) & $9(8.5)$ & $5(9.3)$ & $4(7.7)$ & 1.00 \\
\hline $\mathrm{AZT} / \mathrm{TDF}+3 \mathrm{TC} / \mathrm{FTC}+\mathrm{NVP}$ & $8(88.9)$ & $4(80.0)$ & $4(100.0)$ & \\
\hline$A Z T+3 T C+E F V$ & $1(11.1)$ & $1(20.0)$ & $0(0.0)$ & \\
\hline PMTCT and postnatal maternal ART & $10(9.4)$ & $7(13.0)$ & $3(5.8)$ & 0.32 \\
\hline PMTCT & & & & 1.00 \\
\hline sdNVP-based PMTCT & $2(20.0)$ & $2(28.6)$ & $0(0.0)$ & \\
\hline Other than sdNVP-based PMTCT & $8(80.0)$ & $5(71.4)$ & $3(100.0)$ & \\
\hline Postnatal maternal HAART & & & & 1.00 \\
\hline $\mathrm{AZT} / \mathrm{TDF}+3 \mathrm{TC} / \mathrm{FTC}+\mathrm{NVP}$ & $8(80.0)$ & $5(71.4)$ & $3(100.0)$ & \\
\hline$A Z T+3 T C+L P V / r$ & $2(20.0)$ & $2(28.6)$ & $0(0.0)$ & \\
\hline PMTCT only & $32(30.2)$ & $15(27.8)$ & $17(32.7)$ & 0.58 \\
\hline Only sdNVP-based PMTCT & $5(15.6)$ & $3(20.0)$ & $2(11.8)$ & \\
\hline Other than sdNVP-based PMTCT & $27(84.4)$ & $12(80.0)$ & $15(88.2)$ & \\
\hline Postnatal maternal ART only & $13(12.3)$ & $7(13.0)$ & $6(11.5)$ & 0.82 \\
\hline $\mathrm{D} 4 \mathrm{~T} / \mathrm{AZT}+3 \mathrm{TC}+\mathrm{NVP}$ & $8(61.5)$ & $4(57.1)$ & $4(66.7)$ & \\
\hline $\mathrm{AZT} / \mathrm{D} 4 \mathrm{~T} / \mathrm{TDF}+3 \mathrm{TC} / \mathrm{FTC}+\mathrm{EFV}$ & $3(23.1)$ & $2(28.6)$ & $1(16.7)$ & \\
\hline $\mathrm{D} 4 \mathrm{~T}+3 \mathrm{TC}+\mathrm{LPV} / \mathrm{r}$ & $1(7.7)$ & $0(0.0)$ & $1(16.7)$ & \\
\hline Missing & $1(7.7)$ & $1(14.3)$ & $0(0.0)$ & \\
\hline No previous exposure to any PMTCT or maternal ART & $42(39.6)$ & $20(37.0)$ & $22(42.3)$ & 0.58 \\
\hline \multicolumn{5}{|l|}{ Z-scores at child's ART initiation, mean (SD) } \\
\hline Weight-for-age & $-2.3(1.5)$ & $-2.3(1.4)$ & $-2.3(1.6)$ & 0.81 \\
\hline Height-for-age & $-2.2(1.7)$ & $-2.1(1.7)$ & $-2.3(1.7)$ & 0.53 \\
\hline Weight-for-height & $-1.5(1.4)$ & $-1.5(1.3)$ & $-1.4(1.5)$ & 0.84 \\
\hline WHO stage & & & & 0.86 \\
\hline Stage 1 or $2, \mathrm{n}(\%)$ & $48(45.3)$ & $24(44.4)$ & $24(46.2)$ & \\
\hline Stage 3 or $4, \mathrm{n}(\%)$ & $58(54.7)$ & $30(55.6)$ & $28(53.9)$ & \\
\hline Haemoglobin (g/dL), median (IQR) & $9.2(8.4-9.9)$ & $9.1(8.5-10.0)$ & $9.4(8.4-9.9)$ & 0.75 \\
\hline CD4 \%, median (IQR) & $20.8(14.2-28.1)$ & $18.9(13.9-27.4)$ & $21.2(15.0-28.8)$ & 0.65 \\
\hline Viral load (log $\operatorname{lop}_{10}$ copies/mL), median (SD) & $6.1(1.0)$ & $6.2(1.0)$ & $6.0(1.0)$ & 0.51 \\
\hline Viral load $\geq 6 \log _{10}$ copies/mL, n (\%) & $58(54.7)$ & $30(55.6)$ & $28(53.8)$ & 0.86 \\
\hline
\end{tabular}


Table 1 Baseline characteristics according to randomisation arm of the 106 HIV-1-infected children randomised in the ANRS 12206 MONOD trial (Abidjan and Ouagadougou, May 2011-April 2014) (Continued)

\begin{tabular}{|c|c|c|c|c|}
\hline First-line NRTI backbone & & & & 0.31 \\
\hline ZDV-3TC, n (\%) & 95 (89.6) & $50(92.6)$ & $45(86.5)$ & \\
\hline ABC-3TC, n (\%) & $11(10.4)$ & $4(7.4)$ & $7(13.5)$ & \\
\hline Ever start cotrimoxazole, n (\%) & $104(98.1)$ & $53(98.1)$ & $51(98.1)$ & 1.00 \\
\hline \multicolumn{5}{|l|}{ At randomisation } \\
\hline Age (months), median (IQR) & $26.8(21.5-31.5)$ & $26.0(21.8-31.3)$ & $27.2(20.8-31.5)$ & 0.84 \\
\hline Duration on HAART (months), median (IQR) & $12.7(12.1-13.0)$ & $12.7(12.1-13.0)$ & $12.6(12.1-13.0)$ & 0.86 \\
\hline Weight (kg), median (IQR) & $10.2(9.2-11.4)$ & $10.2(9.3-11.2)$ & $10.2(9.1-11.6)$ & 0.92 \\
\hline WHO stage 3 or $4, \mathrm{n}(\%)$ & $49(46.2)$ & $25(46.3)$ & $24(46.1)$ & 0.99 \\
\hline CD4 \%, median (IQR) & $35.9(28.5-40.9)$ & $36.4(28.5-40.7)$ & $34.9(28.5-41.1)$ & 0.63 \\
\hline On cotrimoxazole, n (\%) & $106(100.0)$ & $54(100.0)$ & $52(100.0)$ & - \\
\hline
\end{tabular}

AZT Zidovudine, ABC Abacavir, 3TC Lamivudine, LPV/r Lopinavir-boosted ritonavir, EFV Efavirenz, IQR Interquartile range, ART Antiretroviral therapy, TDF Tenofovir, FTC Emtricitabine, NVP Nevirapine, PMTCT Prevention of mother-to-child-transmission, sdNVP Single-dose nevirapine, HAART Highly active antiretroviral therapy, D4T Stavudine, SD Standard deviation, WHO World Health Organization, NRTI Nucleoside reverse transcriptase inhibitor

these 14 children with virological failure at 12 months post-switch, samples prior to ART initiation were analysed retrospectively: three out of seven (43\%) from each arm had pre-ART NNRTI-resistance mutations. When comparing the resistance profile 12 months postrandomisation to that observed prior to ART initiation, a non-significant trend towards a higher rate of emerging NNRTI resistance mutations was observed in the EFV arm compared to the LPV arm: five out of six (83\%) vs. two out of seven (29\%), respectively (Fisher's exact test, $p=0.10$ ). We also noted a high NNRTI-resistance mutation rate prior to ART initiation in the LPV group, reaching 46\% (6 out of 13) in children failing at 12 months, even if they were not exposed to PMTCT interventions, probably acquired postnatally via breastmilk from their mother who was initiated on ART before the child. In contrast, five out

Table 2 Twelve-month post-randomisation primary and secondary outcomes in the 106 HIV-1-infected children randomised in the ANRS 12206 MONOD study according to arm (Abidjan and Ouagadougou, February 2013-April 2015)

\begin{tabular}{|c|c|c|c|c|}
\hline 12-month outcomes & Total $N=106$ & $\begin{array}{l}\text { Arm 1: AZT }+3 T C+L P V / r \\
\text { (twice daily) } N=54\end{array}$ & $\begin{array}{l}\text { Arm 2: } A B C+3 T C+E F V \\
\text { (once daily) } N=52\end{array}$ & $p$ value \\
\hline Follow-up (months), median (IQR) & $12.7(12.1-13.0)$ & $12.7(12.1-13.0)$ & $12.6(12.1-13.0)$ & 0.44 \\
\hline Death & $0(0.0)$ & $0(0.0)$ & $0(0.0)$ & - \\
\hline Loss to follow-up & $0(0.0)$ & $0(0.0)$ & $0(0.0)$ & - \\
\hline Withdrawal & $0(0.0)$ & $0(0.0)$ & $0(0.0)$ & - \\
\hline Virological success ( $V L$ < 500 copies $/ m L)$ & $89(84.0)$ & $46(85.2)$ & $43(82.7)$ & 0.72 \\
\hline Virological failure (500 $\geq \mathrm{VL}<1000$ copies/mL) & $3(2.8)$ & $1(1.8)$ & $2(3.8)$ & - \\
\hline Virological failure (VL $\geq 1000$ copies/mL) & $14(13.2)$ & $7(13.0)$ & $7(13.5)$ & 0.59 \\
\hline CD4 \%, median (IQR) & $37.3(31.6-41.9)$ & $37.3(31.3-41.6)$ & $37.1(31.6-42.0)$ & 0.85 \\
\hline Immunodeficiency for age ${ }^{a}$ & & & & 0.59 \\
\hline None & $57(53.8)$ & $32(59.3)$ & $25(48.1)$ & \\
\hline Mild & $38(35.9)$ & $17(31.5)$ & $21(40.4)$ & \\
\hline Severe & $3(2.8)$ & $2(3.7)$ & $1(1.9)$ & \\
\hline Missing & $8(7.6)$ & $3(5.6)$ & $5(9.6)$ & \\
\hline \multicolumn{5}{|l|}{ Z-score, mean (SD) } \\
\hline Weight-for-age & $-1.2(0.9)$ & $-1.3(0.8)$ & $-1.2(1.0)$ & 0.63 \\
\hline Height-for-age & $-1.4(1.1)$ & $-1.5(1.1)$ & $-1.4(1.2)$ & 0.84 \\
\hline Weight-for-height & $-0.6(0.8)$ & $-0.6(0.9)$ & $-0.5(0.8)$ & 0.62 \\
\hline
\end{tabular}

AZT Zidovudine, ABC Abacavir, 3TC Lamivudine, LPV/r Lopinavir-boosted ritonavir, EFV Efavirenz, IQR Interquartile range, VL Viral load, SD Standard deviation ${ }^{a}$ Severe immunodeficiency for age: CD4 $<25 \%$ if aged $<2$ years, CD4 $<20 \%$ if aged $\geq 2$ years; mild immunodeficiency for age: CD4 between 25 and $35 \%$ if aged $<2$ years, CD4 between 20 and $35 \%$ if aged $\geq 2$ years; No immunodeficiency for age if CD4 $>35 \%$ 
Table 3 Factors associated with 12-month virological success ( $<500$ copies $/ \mathrm{mL}$ ) in the $106 \mathrm{HIV}$-1-infected children randomised in the ANRS 12206 MONOD study (Abidjan and Ouagadougou, February 2013-February 2015)

\begin{tabular}{|c|c|c|c|c|}
\hline & Total $N=106$ & $\begin{array}{l}\text { Virological success } \\
(<500 \text { copies } / \mathrm{mL}) \mathrm{N}=89\end{array}$ & $\begin{array}{l}\text { Virological failure } \\
(\geq 500 \text { copies } / \mathrm{mL}) N=17\end{array}$ & $p$ value \\
\hline Country & & & & 0.83 \\
\hline Abidjan & $71(67.0)$ & $60(67.4)$ & $11(64.7)$ & \\
\hline Ouagadougou & $35(33.0)$ & $29(32.6)$ & $6(35.3)$ & \\
\hline Sex & & & & 0.81 \\
\hline Female & $59(55.7)$ & $50(56.2)$ & $9(52.9)$ & \\
\hline Male & $47(44.3)$ & $39(43.8)$ & $8(47.1)$ & \\
\hline Treatment arm & & & & 0.73 \\
\hline$A Z T / A B C+3 T C+L P V / r$ & $54(50.9)$ & $46(51.7)$ & $8(47.1)$ & \\
\hline$A B C+3 T C+E F V$ & $52(49.1)$ & $43(48.3)$ & $9(52.9)$ & \\
\hline Main caregiver for children & & & & 1.00 \\
\hline Mother main caregiver & $88(83.0)$ & $74(83.2)$ & $14(82.4)$ & \\
\hline Father/other in charge of care & $18(17.0)$ & $15(16.8)$ & $3(17.6)$ & \\
\hline Father informed of the child's HIV status & & & & 0.30 \\
\hline No & $44(41.5)$ & $35(39.3)$ & $9(52.9)$ & \\
\hline Yes & $62(58.5)$ & $54(60.7)$ & $8(47.1)$ & \\
\hline History of antiretroviral drug exposure & & & & 0.63 \\
\hline Prenatal maternal ART & $9(8.5)$ & $7(7.9)$ & $2(11.8)$ & \\
\hline PMTCT only & $32(30.2)$ & $27(30.3)$ & $5(29.4)$ & \\
\hline Postnatal maternal ART only & $13(12.3)$ & $12(13.5)$ & $1(5.9)$ & \\
\hline PMTCT and postnatal maternal ART & $10(9.4)$ & $7(7.9)$ & $3(17.6)$ & \\
\hline No previous exposure to any PMTCT or ART & $42(39.6)$ & $36(40.4)$ & $6(35.3)$ & \\
\hline Age at randomisation & & & & 0.39 \\
\hline$<24$ months & $41(38.7)$ & $36(40.4)$ & $5(29.4)$ & \\
\hline$\geq 24$ months & $65(61.3)$ & $53(59.6)$ & $12(70.6)$ & \\
\hline \multicolumn{5}{|l|}{ WHO clinical stage at randomisation } \\
\hline Stage $1,2,3$ & $83(78.3)$ & $73(82.0)$ & $10(58.8)$ & 0.05 \\
\hline Stage 4 & $23(21.7)$ & $16(18.0)$ & $7(41.2)$ & \\
\hline Z-score Weight-for-age at ART initiation & & & & 0.35 \\
\hline Normal & $50(47.2)$ & $44(49.4)$ & $6(35.3)$ & \\
\hline Moderate & $22(20.7)$ & $19(21.4)$ & $3(17.6)$ & \\
\hline Severe & $34(32.1)$ & $26(29.2)$ & $8(47.1)$ & \\
\hline Z-score Height-for-age at ART initiation & & & & 0.09 \\
\hline Normal & $55(51.9)$ & $50(56.2)$ & $5(29.4)$ & \\
\hline Moderate & $21(19.8)$ & $15(16.8)$ & $6(35.3)$ & \\
\hline Severe & $30(28.3)$ & $24(27.0)$ & $6(35.3)$ & \\
\hline CD4 \% at ART initiation & & & & 0.60 \\
\hline$>35 \%$ & $13(12.3)$ & $10(11.2)$ & $3(17.6)$ & \\
\hline $25-35 \%$ & $19(17.9)$ & $17(19.1)$ & $2(11.8)$ & \\
\hline$<25 \%$ or missing & $74(69.8)$ & $62(69.7)$ & $12(70.6)$ & \\
\hline
\end{tabular}

Data are presented as $\mathrm{n}(\%)$

AZT Zidovudine, 3TC Lamivudine, ABC Abacavir, EFV Efavirenz, LPV/r Lopinavir-boosted ritonavir, ART Antiretroviral therapy, PMTCT Prevention of mother-to-childtransmission, WHO World Health Organization. Normal: Z-score $\geq 2$ Standard Deviations (SD); Z-score $<-2$ SD corresponds to moderate malnutrition, being severe form at a Z-score<-3 SD 
Table 4 Factors associated with 12-month virological success ( $<500$ copies $/ \mathrm{mL})$ in the $106 \mathrm{HIV}$-1-infected children randomised in the ANRS 12206 MONOD study (Abidjan and Ouagadougou, February 2013-February 2015): logistic regression

\begin{tabular}{|c|c|c|c|c|c|c|}
\hline & Univ & & & Adjus & $\mathrm{del}^{\mathrm{a}}$ & \\
\hline & $\overline{\mathrm{OR}}$ & $\mathrm{Cl}(95 \%)$ & $p$ value & $\overline{a O R}$ & $\mathrm{Cl}(95 \%)$ & $p$ value \\
\hline Abidjan vs. Ouagadougou & 1.13 & $(0.38-3.35)$ & 0.83 & 0.64 & $(0.17-2.41)$ & 0.51 \\
\hline Female vs. Male & 1.14 & $(0.40-3.23)$ & 0.81 & 1.26 & $(0.41-3.93)$ & 0.68 \\
\hline Treatment arm & & & 0.73 & & & 0.66 \\
\hline$A Z T / A B C+3 T C+L P V / r$ & Ref. & - & & Ref. & - & \\
\hline$A B C+3 T C+E F V$ & 0.83 & $(0.29-2.35)$ & & 0.78 & $(0.26-2.38)$ & \\
\hline Mother main caregiver vs. father or other & 1.06 & $(0.27-4.14)$ & 0.94 & - & - & \\
\hline Father informed of HIV status of the child & 1.74 & $(0.61-4.93)$ & 0.30 & - & - & \\
\hline History of antiretroviral drug exposure & & & 0.68 & & & 0.34 \\
\hline No previous exposure to any PMTCT or ART & Ref. & - & & Ref. & - & \\
\hline Prenatal maternal ART & 0.58 & $(0.10-3.51)$ & & 0.32 & $(0.04-2.32)$ & \\
\hline Exposure to PMTCT only & 0.90 & $(0.25-3.26)$ & & 0.64 & $(0.15-2.68)$ & \\
\hline Exposure to postnatal maternal ART only & 2.00 & $(0.22-18.33)$ & & 1.95 & $(0.20-19.24)$ & \\
\hline PMTCT and postnatal maternal ART & 0.39 & $(0.08-1.94)$ & & 0.19 & $(0.03-1.21)$ & \\
\hline Age at randomisation $<24$ months & 1.63 & $(0.53-5.03)$ & 0.39 & - & - & \\
\hline WHO clinical stage at randomisation & & & 0.04 & & & 0.01 \\
\hline Stage $1,2,3$ & Ref. & - & & Ref. & - & \\
\hline Stage 4 & 0.31 & $(0.10-0.95)$ & & 0.18 & $(0.05-0.72)$ & \\
\hline
\end{tabular}

OR Odds ratio, Cl Confidence interval, aOR Adjusted odds ratio, AZT Zidovudine, 3TC Lamivudine, LPV/r Lopinavir-boosted ritonavir, ABC Abacavir, EFV Efavirenz, $P M T C T$ Prevention of mother-to-child-transmission, ART Antiretroviral therapy, WHO World Health Organization

${ }^{a}$ Forced variables: country, sex, treatment arm and history of antiretroviral drug exposure

of six children $(83 \%)$ in the EFV arm developed a new incident NNRTI-resistance mutation that emerged after the switch. Of note, one child in the EFV arm, prior to ART initiation, harboured a virus resistant to both NRTIs and NNRTIs (mutations M41L, L74I, V108I, M184V, L210W, T215Y, K101E, Y181C, P225H); he/she was born to a mother who had been on ART (AZT-3TC-NVP) for seven years. The four children (two in each arm) exposed to maternal ART through breast milk had new mutations to NNRTI at virological failure.

\section{Discussion}

Our trial provides original findings in the West African context among young HIV-infected children both exposed and not exposed to PMTCT intervention, and virologically suppressed after 12-15 months of a LPVbased ART initiated before 2 years of age. Despite a high-quality follow-up, our randomised trial could not demonstrate non-inferiority for a switch to EFV from $\mathrm{LPV} / \mathrm{r}$ with regard to the primary outcome (a VL $<500$ copies $/ \mathrm{mL}$ ) when using both intention-to-treat and perprotocol analyses. Based on completed trial data, the actual statistical power was $67 \%$ to detect the planned difference in this outcome. When considering the secondary outcome of HIV RNA $<1000$ copies/mL, which is commonly used to inform ART switching decisions worldwide, we did demonstrate the non-inferiority of
EFV compared to LPV/r. We also showed that switching to a simplified EFV-based therapy in virologically suppressed children below 3 years of age is safe, with no deaths and very few severe adverse events, all of which were infectious in nature. However, the pre-switch resistance profiles observed among children with virological failure at 12 months post-switch revealed high rates of NNRTI resistance prior to ART initiation, even in those not exposed to single-dose NVP for PMTCT in both groups. We presume this is due to PMTCT exposure and to postnatal antiretroviral drug exposure through breast milk. New NNRTI mutations were also observed in the EFV arm in children for whom virological suppression failed. We therefore recommend that any simplification switch to EFV needs to be closely monitored.

To date, LPV-sparing strategies have been explored in two paediatric trials in South Africa. These results were firstly reported in the NEVEREST-2 trial, with a switch to a NVP-based ART after first-line ART based on LPV/ $r$ [22]. Results from NEVEREST-2 showed that virological suppression at $<50$ copies $/ \mathrm{mL}$ at 52 weeks was significantly more common in the NVP "Switch" group (56\%) compared to the LPV/r "Stay" group (42\%), but remained low overall. However, when the outcome measure was a virological response at $<1000$ copies/mL, the LPV/r group did significantly better, with $98 \%$ suppression vs. $78 \%$ for the NVP group $(p<0.001)$. The 
Table 5 Incidence of post-randomisation grade 3 and 4 adverse events in the $106 \mathrm{HIV}$-1-infected children randomised in the ANRS 12206 MONOD study according to arm (Abidjan and Ouagadougou, February 2013-April 2015)

\begin{tabular}{|c|c|c|c|c|}
\hline Outcomes & Total $N=106$ & $\begin{array}{l}\text { Arm 1: } A Z T / A B C+3 T C+L P V / r \\
\text { (twice daily) } N=54\end{array}$ & $\begin{array}{l}\text { Arm 2: } A B C+3 T C+E F V \\
\text { (once daily) } N=52\end{array}$ & $p$ value \\
\hline \multicolumn{5}{|l|}{ SAE } \\
\hline Hospitalisations and clinical SAE & $6(5.7)$ & $2^{d}(3.7)$ & $4^{e}(7.7)$ & 0.43 \\
\hline Grade 3 or 4 adverse events ${ }^{a}$ & $1(0.9)$ & $0(0.0)$ & $1(1.9)$ & 0.90 \\
\hline Toxicity causing ART modification ${ }^{\mathrm{b}}$ & $3(2.8)$ & $1(1.9)$ & $2(3.8)$ & 0.61 \\
\hline Sleeping disorders declared by caregivers & $9(8.5)$ & $4(7.4)$ & $5(9.6)$ & 0.74 \\
\hline \multicolumn{5}{|l|}{ Specific biological adverse events ${ }^{c}$} \\
\hline Anaemia, grade 3 and 4 & $3(2.8)$ & $1(1.9)$ & $2(3.8)$ & 0.61 \\
\hline Neutropenia, grade 3 and 4 & $10(9.4)$ & $9(16.7)$ & $1(1.9)$ & 0.02 \\
\hline Thrombopenia, grade 3 and 4 & $1(0.9)$ & $1(1.9)$ & $0(0.0)$ & 1.00 \\
\hline Hyperglycaemia, grade 3 and 4 & $0(0.0)$ & $0(0.0)$ & $0(0.0)$ & - \\
\hline Hypercholesterolemia, grade 3 & $0(0.0)$ & $0(0.0)$ & $0(0.0)$ & - \\
\hline Hypertriglyceridemia, grade 3 and 4 & $0(0.0)$ & $0(0.0)$ & $0(0.0)$ & - \\
\hline Hypercreatininaemia, grade 3 and 4 & $0(0.0)$ & $0(0.0)$ & $0(0.0)$ & - \\
\hline Hypertransaminasaemia AST or ALT, grade 3 and 4 & $2(1.9)$ & $1(1.9)$ & $1(1.9)$ & 1.00 \\
\hline Hyperbilirubinaemia, grade 3 and 4 & $5(4.7)$ & $3(5.6)$ & $2(3.9)$ & 1.00 \\
\hline Hyperamylasaemia, grade 3 and 4 & $2(1.9)$ & $0(0.0)$ & $2(3.9)$ & 0.24 \\
\hline Hyperlipasaemia, grade 3 and 4 & $0(0.0)$ & $0(0.0)$ & $0(0.0)$ & - \\
\hline
\end{tabular}

Data are presented as $\mathrm{n}(\%)$

AZT Zidovudine, 3TC Lamivudine, LPV/r Lopinavir-boosted ritonavir, ABC Abacavir, EFV Efavirenz, SAE Serious adverse events, ART Antiretroviral therapy, AST Aspartate transaminase, $A L T$ Alanine transaminase

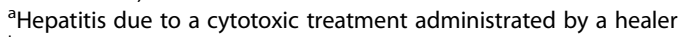

${ }^{b}$ One toxicity substitution in a child randomised to LPV/r was from AZT to ABC for neutropenia. Two toxicity substitutions in children randomised to EFV to LPV arm: one for sleeping disorders persisting 10 months after randomisation and one for hypertransaminasaemia due to a cytotoxic treatment administrated by a healer

${ }^{\mathrm{C}}$ No other biological SAE including glycaemia, cholesterolaemia, triglyceridaemia, creatininaemia, lipaseamia

${ }^{\mathrm{d}} 2$ gastroenteritis

e 1 gastroenteritis, 1 pneumonia, 1 upper respiratory infection with malaria, 1 malaria

second protease inhibitor-sparing trial was the NEVEREST-3 trial, published in November 2015, which evaluated a switch to EFV-based ART after LPV/r, similar to our trial [23]. At the time of randomisation, children were on average 4 years of age and had been on treatment for 3.5 years. NEVEREST-3 reported a significantly higher rate of viral rebound to $>50$ copies $/ \mathrm{mL}$ in the LPV/r group $(n=148)$ than in the EFV group $(n=$ 150), therefore in favour of EFV: $28 \%$ of children in the $\mathrm{LPV} / \mathrm{r}$ experienced an episode of viral rebound vs. $18 \%$ in the EFV group. For the second primary endpoint, virological failure $(\geq 1000$ copies $/ \mathrm{mL})$, there was no significant difference between the groups: $2 \%$ of children in $\mathrm{LPV} / \mathrm{r}$ experienced confirmed virological failure vs. $2.7 \%$ of children in the EFV group. The authors concluded that children previously exposed to NVP prophylaxis for PMTCT and initially suppressed on a LPV/r-based regimen did not experience higher rates of viral rebound or virological failure, and can safely switch to an EFV-based regimen [22]. Among the seven children with virological failure, genotyping revealed that three children (42\%) had a NNRTI-resistance mutation (K103N) at failure.
However, there are several differences between the NEVEREST-3 trial and our trial: all children from NEVEREST-3 were systematically exposed to single-dose NVP for PMTCT and mainly issued from a trial study design; rates of malnutrition (interacting with antiretroviral pharmacokinetics) are lower in South Africa, and viral subtypes differ. Children were younger at ART initiation (median of 9.3 months in NEVEREST-3 vs. 13.7 months in MONOD); at the time of switch, children were 2 years older in NEVEREST-3 compared to MONOD (median 4.3 years vs. 26.8 months, respectively), with, consequently, a 36-month longer duration of viral suppression before randomisation for the switch (3.5 years vs. 12 months); the EFV dosage was higher in the MONOD trial compared to the NEVEREST-3 trial $(200 \mathrm{mg} /$ day for a weight of $10-13.9 \mathrm{~kg})$. Our eligibility criteria at randomisation considered children aged $<3$ years. Currently, EFV is not recommended in children $<3$ years due to dosing difficulties and the concern for neurological adverse events [24]. However, the FDA approved dosing for children aged 3 months to $<3$ years as follows: $3.5-5 \mathrm{~kg}$, two $50 \mathrm{mg}$ capsules; $5-7.5 \mathrm{~kg}$, three 


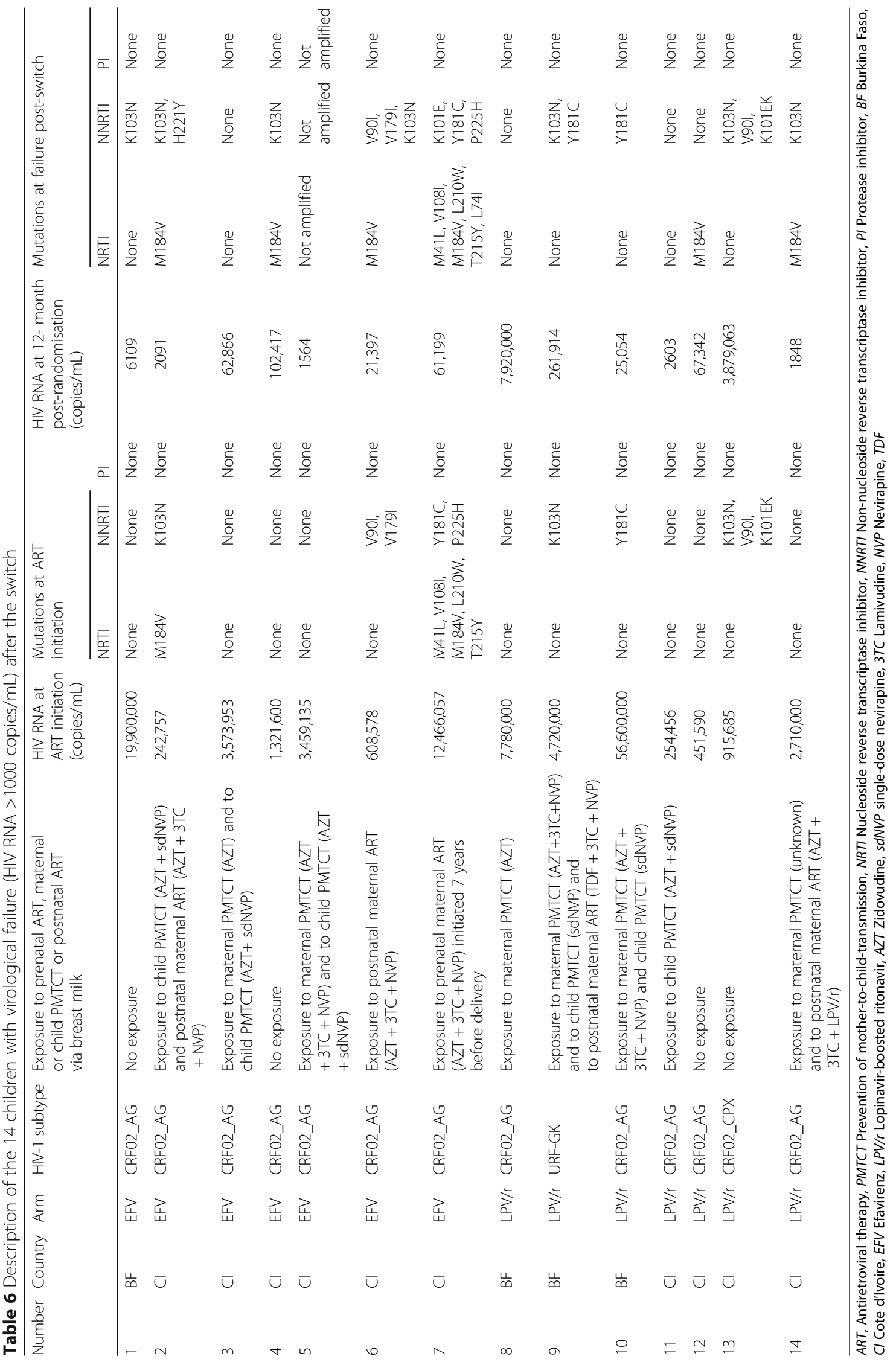


$50 \mathrm{mg}$ capsules; 7.5-15 kg, one $200 \mathrm{mg}$ capsule (http:// www.who.int/hiv/pub/guidelines/arv2013/download/en/ index.html). The dosing of EFV in our trial was $25 \mathrm{mg} /$ $\mathrm{kg}$, higher than that recommended [7]. While the minimum age of children in the modelling study of EFV PKs was 2.7 years [16], PK studies are ongoing to identify the appropriate dosage in this population and to provide guidance. Importantly, we did not observe any severe neurological adverse events in our children. Although we were not able to provide data using the $<50$ copies/ $\mathrm{mL}$ threshold given the available laboratory assays in our trial, we found similar outcomes to the NEVEREST-3 trial when considering the difference between arms outcome of $\geq 1000$ copies $/ \mathrm{mL}$.

We observed high rates of NNRTI resistance in those children who failed to develop virological suppression both before and after failure in both arms. A high frequency of transmitted NNRTI-resistance mutations is expected after exposure to NNRTI-based ART for PMTCT [25]. In addition, we show here that children who have not been exposed to PMTCT are at a very high risk of developing a number of resistance mutations through their exposure to suboptimal doses of maternal antiretroviral drugs through maternal breast milk. Multiclass resistance arises frequently in HIV-infected breastfeeding infants whose mothers are initiated on ART postnatally $[26,27]$. These emerging mutations are expected to increase in the context of a large scale-up in maternal ART coverage through the rollout of Option B+. These drug-resistance mutations might negatively impact on future antiretroviral strategies in children who become HIV-infected in a context of limited therapeutic options. However, we did not observe higher rates of failure in the EFV switch arm relative to the $\mathrm{LPV} / \mathrm{r}$ arm, despite these high pre-ART rates. The accumulation of new NNRTI-resistance mutations was common in children switching to EFV. This suggests that more children who experience virological failure could be expected to accumulate NNRTI-resistance mutations [28]. No resistance mutations to protease inhibitors were detected in our study. Therefore, it is critical that the first-line ART for the growing number of HIV-infected children frequently exposed to suboptimal doses of antiretroviral drugs includes medications with high genetic barriers against resistance.

Finally, it is noteworthy that the implementation of our trial project was operationally complex, resulting in delayed ART initiation at a median age of 14 months, and high mortality in HIV-infected children before ART. During the recruitment period, the national AIDS programmes in both study countries had very low early infant diagnosis (EID) coverage, estimated at $29 \%$ in Ouagadougou [29] and 16\% in Abidjan [30], mainly due to the post-electoral crisis in 2011. Partially because of this late access to care for infants with HIV infection, the proportion of children alive, in care, and with virological suppression after 12-15 months of LPV was lower than expected: $68 \%$ overall, instead of the $90 \%$ expected. This led to fewer children with a confirmed undetectable VL at a 3-month interval being eligible for randomisation, affecting the actual statistical power of our trial. We extended the inclusion period to increase the number of children randomised, but for funding reasons, it was not possible to extend this recruitment period beyond February 2013. This highlights that access to EID and early ART before the age of 2 years still remains challenging in real life in 2015. The scale-up of recommended early ART (before 12 months of age) remains one of the major public health challenges in resource-limited settings $[29,31]$. Indeed, access to ART in infants requires systematic EID by virological testing in the first weeks of life. EID is complex, expensive and poorly accessible in many African settings [31, 32]. Rollout of EID has been limited, particularly in West African settings where HIV prevalence is low [29, 30, 33]. While LPV-based first-line ART remains the most effective regimen for children aged $<3$ years, a place for NVPbased first-line ART might be also acknowledged when protease inhibitors are not accessible, even in children exposed to single-dose NVP. Indeed, the ARROW randomised trial recently showed no differences in virological suppression and in resistance to NRTIs or NNRTIs at week 144 between children exposed or unexposed to single-dose NVP prophylaxis receiving NNRTIbased ART and aged $<3$ years [34].

Several pitfalls should be considered in our trial. The use of a high cut-off to define viral suppression could have led to the accumulation of antiretroviral drugresistance mutations in the long term. However, this should not have affected the comparability between arms. Also, we were unable to explore the minimal duration of first-line therapy needed to allow a successful switch; our results suggest that it should be at least 12 months. In our trial, the switch to an EFV strategy was conducted only in children with documented virological suppression, leading to a limited generalisability of our approach in settings where HIV VL monitoring is less available, but this was considered to be more ethical to avoid a lack of equipoise in children failing the initial LPV-based therapy. Finally, we were not able to accurately assess adherence using caregiver questionnaires about missing doses during the last 4 days before each monthly visit, but we are currently investigating these data using PK measurements.

\section{Conclusions}

Both the NEVEREST-3 [22] and the MONOD trials provide guidance on the feasibility of switching a child 
initiated on LPV-based ART to EFV. In our trial, we were unable to conclude on the non-inferiority of EFV compared to LPV at the 500 copies/mL threshold, due to the large confidence interval of the difference, but it was conclusive beyond 1000 copies $/ \mathrm{mL}$, similar to the NEVEREST-3 trial. However, given the high rate of NNRTI-resistance mutations at ART initiation in children who failed to develop virological suppression, and the emergence of newly acquired mutations at 12-months post-randomisation (compared to those mutations present at ART initiation) in these children, we would like to be cautious in recommending this switching strategy as a routine public health strategy in low-income countries: this switch strategy needs to be considered only in children with good adherence profiles, and when VL monitoring is available to detect early virological failure after the switch. In settings where ART is delayed and treating young infants remains a significant challenge, with potential exposure to suboptimal doses of maternal antiretroviral drugs through maternal breast milk, it will be particularly crucial to preserve those on suppressive ART of any type, but ideally with a high genetic barrier. In situations where VL monitoring is available before and after the switch, a switch to an EFV-based regimen may be a valuable individualised option in virologically suppressed children with good clinical and adherence profiles. Finally, new formulations of $\mathrm{LPV} / \mathrm{r}$ that are more palatable and less costly, as well as other future drug options, are still urgently needed to increase ART response in children. Minitab sprinkles formulations of LPV/r are now available but remain poorly palatable [35]. Because treating young children remains challenging in Africa, there is an urgent need to develop formulations appropriate for young children and to make protease inhibitors more widely available, in order to improve the initial response to ART in children. Futures studies are also needed to assess its field response in routine programmes. The potent integrase inhibitor dolutegravir, which has a very low risk for drugresistance mutations and is currently being formulated for paediatric populations, may represent a valuable option as a first-line therapy or to replace EFV in a switch strategy and needs to be assessed in the future [36].

\section{Acknowledgements}

We thank the children, their families and the staff from all participating centres for their dedication. We warmly thank Andrea Ciaranello for her helpful comments on an early draft, Valérie Journot for her helpful statistical advice, and Sophie Desmonde for editing. We thank the MONOD ANRS 12206 trial independent data monitoring committee meeting: Dominique Costagliola (Chair; Paris, France), Mark Cotton (Cape Town, South Africa), Carlo Giaquito (Bologna, Italie), Diana Gibb (London, UK) and Elisabeth Menu (Paris, France). Désiré Dahourou PhD was funded by the ANRS (ANRS12206-B89). Malik Coulibaly PhD was funded by EDCTP-ANRS-LIH. The ANRS 12206 MONOD Collaboration Study Group (as of 7 July 2015): Participating sites.

Burkina Faso, Ouagadougou: Centre de Recherche International pour la Santé: Malik Coulibaly, Désiré Lucien Dahourou, Nicolas Meda (co-investigator), Colette Ouédraogo, Mamadou Sawadogo, Wilfried Somé, Désiré Sondo, Elisabeth Thio.
CHU Charles De Gaulle: Mamadou Barry, William Hiembo, Fla Kouéta, Adama Ouattara, Moussa Ouédraogo, Rasmata Ouédraogo, Sylvie Ouédraogo, Bernadette Congo, Rose Barry, Diarra Yé. CHU Yalgado Ouédraogo: Malika Congo, Edouard Minéné, Marie Coulibaly, Pierre Innocent Guissou Angèle Kalmogho, Ludovic Kam, Emile Ouédraogo, Lassana Sangaré, Caroline Yonaba. Programme Sectoriel Santé de Lutte contre le SIDA et les IST: Sylvestre Tiendrebeogo. Programme d'Appui au Monde Associatif et Communautaire (PAMAC): Odette Ky-Zerbo.

Côte d'Ivoire, Abidjan: Programme PACCl: Xavier Anglaret, Clarisse Amani-Bossé, Divine Avit, Christine Danel, Serge Eholié, Didier Ekouévi, Eulalie Kanga, Suzanne Kouadio, Séverin Lennaud, Maxime Aimé Oga, Thérèse N'Dri-Yoman. CHU Cocody: Madeleine Amorissani-Folquet, Evelyne Dainguy, Beugre Kouassi, Jean-Claude Kouassi, Gladys Oka. CHU Yopougon: Kader Keita, Jean Yves Lambin, François Eboua Tanoh, Marguerite Timité-Konan (co-investigator). Site Abobo-Avocatier: Véronique Mea-Assande. Site CePReF-enfants: Addi Edmond Aka, Hortense Aka-Dago, Sylvie N'Gbeche, Eugène Messou. Laboratory CeDReS: Arlette Emieme, Fatoumata Koné, Hervé Menan, Thomas Toni, Vincent Yapo. Programme National de Prise en Charge: Kouamé Abo, Irma Ahoba, David Aka. FSU Abobo-Avocatier: Gbaméné Kouassi. Pharmacie de la Santé Publique: Carine Kodo. Implementers: Touré Siaka, Pety Touré (ACONDA), Fassinou Ekouevi (EGPAF), Ida Viho (ICAP), Anthony Richard Tanoh, Olivier Blé (Fondation ARIEL GLASER). Community representatives: Yaya Coulibaly (RIP+), Philomène Takouo (ONG Bayema). Programme ESTHER: Jean Marie Massumbuko. CIRBA: Kouadio Kouakou. Programme National de Santé Infantile: Dorothée Koumi. Programme Elargi de Vaccination: Berté Koné.

Methodology and Data Management Center: Inserm U897, Institut de Santé Publique, d'Épidémiologie et de Développement, University of Bordeaux, France: Sophie Dattez, Sophie Desmonde, Julie Jesson, Sophie Karcher, Jérôme Le Carrou, Valériane Leroy (coordinating investigator), Karen Malateste, Camille Ndondoki, Pierre Touret. Methodological support: Caroline Bouyssou, Geneviève Chêne, Valérie Conte, Delphine Gabillard, Valérie Journot, Roger Salamon.

MEREVA, Bordeaux. Website: http://mereva.isped.u-bordeaux2.fr/monod/ Accueil.aspx

Supporting teams:

Luxembourg Institute of Health, Luxemburg: Vic Arendt (co-investigator), Carole Devaux, Jean-Claude Schmit.

Hôpital Universitaire Des Enfants Reine Fabiola, Brussels, Belgium: Philippe Lepage (co-investigator)

Hôpital Necker-Enfants Malades-Assistance Publique-Hopitaux de Paris and EA8, Université Paris Descartes: Stéphane Blanche (co-investigator), Deborah Hirt, Christine Rouzioux, Claire Pressiat, Jean-Marc Treluyer, Saik Urien. Commissariat à I'Energie Atomique: Alain Pruvost (CEA), Laboratoire de Virologie, Hopital Saint-Louis: Marie-Laure Chaix-Baudier.

UMR 1058 "Pathogenesis and Control of Chronic Infections" INSERM-Université Montpellier-EFS, Montpellier, France: Philippe Van de Perre (co-investigator). Administrative team: Elodie Vernoux (Bordeaux, France), Aminata Paré-Karambiri (Ouagadougou, Burkina Faso), Zouma Tinto (Ouagadougou, Burkina Faso), Adoulaye Cisse (Abidjan, Côte d'Ivoire), Madikona Dosso (Abidjan, Côte d'Ivoire). MONOD ANRS 12206 Scientific Steering Committee: Roger Salamon (Chair; Bordeaux, France), Valériane Leroy (coordinating investigator; Bordeaux, France), Nicolas Meda (co-investigator; Ouagadougou, Burkina Faso), Marguerite Timite-Konan (co-investigator; Abidjan, Côte d'Ivoire), Vic Arendt (co-investigator; Luxembourg), Stéphane Blanche (co-investigator; Paris, France), Philippe Lepage (co-investigator; Brussels, Belgium), Philippe Van de Perre (co-investigator; Montpellier, France), François Dabis (Bordeaux, France), Jean-Claude Schmit (CRP-Santé, Luxembourg).

Promoter: Inserm-ANRS, France: Jean-François Delfraissy (Director), Brigitte Bazin, Marie de Solère, Claire Rekacewicz.

The content is solely the responsibility of the authors and does not necessarily represent the official views of the French Inserm-ANRS, European Developing Countries Clinical Trials Partnership, or University of Bordeaux.

\section{Funding}

European Developing Countries Clinical Trials Partnership (reference: IP.2007.33011.002), Inserm-ANRS, FNR-Luxembourg. DLD is a PhD student fellow funded by the ANRS (ANRS12206-B89).

\section{Authors' contributions}

$V L, S B, P L, P V d P, R S, N M$ and MTK designed the trial. DD, MC, CY, SO, AK performed the trial in Ouagadougou. MAF, CAB, FE, DA, SN and MTK 
performed the trial in Abidjan. CSD, RO and $T$ were in charge of laboratory analysis. VL and KM wrote the analysis plan. KM did the analysis. VL wrote the first draft of the report. All authors critically revised the manuscript, and read and approved the final version.

\section{Competing interests}

The authors declare that they no competing interests.

\section{Ethical approval and consent to participate}

The protocol was approved by the Comité d'Ethique pour la Recherche en Santé du Burkina Faso, and the Comité National d'Ethique et de la Recherche en Côte d'lvoire. Both parents, if alive, gave their written informed consent for their child to participate.

The sponsor, the French National Agency for Research on AIDS and Viral Hepatitis (ANRS), had no role in the conduct of the study or the interpretation of the data.

\section{Publisher's Note}

Springer Nature remains neutral with regard to jurisdictional claims in published maps and institutional affiliations.

\section{Author details}

'MONOD Project, ANRS 12206, Centre de Recherche Internationale pour la Santé, Ouagadougou, Burkina Faso. ${ }^{2}$ Centre Muraz, Bobo-Dioulasso, Burkina Faso. ${ }^{3}$ Inserm, Unité U1219, Université de Bordeaux, Bordeaux, France. ${ }^{4}$ Paediatric Department, Centre Hospitalier Universitaire of Cocody, Abidjan, Côte d'Ivoire. ${ }^{5}$ PACCI Programme, Site ANRS, Projet MONOD, Abidjan, Côte d'Ivoire. ${ }^{6}$ Department of Infection and Immunity, Luxembourg Institute of Health, Luxembourg City, Luxembourg. 'Laboratory CeDReS, Abidjan, Côte d'Ivoire. ${ }^{8}$ Laboratory, Centre Hospitalier Universitaire de Ouagadougou, Ouagadougou, Burkina Faso. ${ }^{9}$ EA 8, Université Paris Descartes, Paris, France. ${ }^{10}$ Immunology, Hematology, Rhumatologie Unit, Hopital Necker-Enfants Malades-Assistance Publique-Hopitaux de Paris, Paris, France. ${ }^{11}$ Paediatric Department, Centre Hospitalier Universitaire Yalgado Ouédraogo, Ouagadougou, Burkina Faso. ${ }^{12}$ Paediatric Department, Centre Hospitalier Universitaire de Yopougon, Abidjan, Côte d'Ivoire. ${ }^{13}$ Paediatric Department, Hôpital Universitaire des Enfants Reine Fabiola, Université Libre de Bruxelles, Brussels, Belgium. ${ }^{14}$ Paediatric Department, Centre Hospitalier Universitaire Charles de Gaulle, Ouagadougou, Burkina Faso. ${ }^{15}$ UMR 1058, Pathogenesis and control of chronic infections, Inserm/Université de Montpellier/EFS, Montpellier, France. ${ }^{16}$ Department of Bacteriology-Virology, CHU Montpellier, Montpellier, France. ${ }^{17}$ CePReF-enfants, Yopougon, Abidjan, Côte d'Ivoire. ${ }^{18}$ University of Ouagadougou, Ouagadougou, Burkina Faso. ${ }^{19}$ Inserm, Unité U1027, Université Toulouse 3, Toulouse, France.

\section{Received: 31 October 2016 Accepted: 22 March 2017}

Published online: 24 April 2017

\section{References}

1. UNAIDS. Global report UNAIDS report on the global AIDS epidemic 2013. Geneva: UNAIDS; 2013. p. 272.

2. UNAIDS. The Gap Report 2014. ISBN 978-92-9253-062-4. Updated September 2014. Geneva: UNAIDS; 2014. p. 1-422. http://www.unaids.org/sites/default/ files/en/media/unaids/contentassets/documents/unaidspublication/2014/ UNAIDS_Gap_report_en.pdf.

3. Newell M-L, Coovadia H, Cortina-Borja M, Rollins N, Gaillard P, Dabis F. Mortality of infected and uninfected infants born to HIV-infected mothers in Africa: a pooled analysis. Lancet. 2004;364(9441):1236-43.

4. Violari A, Cotton MF, Gibb DM, Babiker AG, Steyn J, Madhi SA, Jean-Philippe P, McIntyre JA. Early antiretroviral therapy and mortality among HIV-infected infants. N Engl J Med. 2008;359(21):2233-44.

5. Report of the WHO Technical Reference Group, Paediatric HIV/ART Care Guideline Group Meeting. Revised treatment recommendations for infants http://www.who.int/hiv/pub/paediatric/WHO_Paediatric_ART_guideline_ rev_mreport_2008.pdf. Accessed 7 Apr 2017.

6. Antiretroviral therapy for HIV infection in infants and children: towards universal access. Recommendations for a public health approach. Revision 2010. https://www.ncbi.nlm.nih.gov/pubmed/23741772. Accessed 7 Apr 2017.
7. Consolidated guidelines on the use of antiretroviral drugs for treating and preventing HIV infection. Recommendations for a public health approach second edition. http://www.who.int/hiv/pub/arv/arv-2016/en/.

8. Guideline on when to start antiretroviral therapy and on pre-exposure prophylaxis for HIV. http://apps.who.int/iris/bitstream/10665/186275/1/ 9789241509565_eng.pdf?ua=1.

9. Palumbo P, Lindsey JC, Hughes MD, Cotton MF, Bobat R, Meyers T, Bwakura-Dangarembizi M, Chi BH, Musoke $\mathrm{P}$, Kamthunzi $\mathrm{P}$, et al. Antiretroviral treatment for children with peripartum nevirapine exposure. N Engl J Med. 2010;363(16):1510-20.

10. Violari A, Lindsey JC, Hughes MD, Mujuru HA, Barlow-Mosha L, Kamthunzi P, Chi BH, Cotton MF, Moultrie H, Khadse S, et al. Nevirapine versus ritonavirboosted lopinavir for HIV-infected children. N Engl J Med. 2012;366(25):2380-9.

11. Yeni P. Rapport du Groupe d'Experts 2008 sur la prise en charge médicale des patients infectées par le VIH, sous la direction du Pr Patrick Yeni. 2008. p. 409. http://social-sante.gouv.fr/IMG/pdf/Rapport_2010_sur_la_ prise_en_charge_medicale_des_personnes_infectees_par_le_VIH_sous_ la_direction_du_Pr-_Patrick_Yeni.pdf

12. Ciaranello AL, Doherty K, Penazzato M, Lindsey JC, Harrison L, Kelly K, Walensky $R P$, Essajee $S$, Losina $E$, Muhe $L$, et al. Cost-effectiveness of first-line antiretroviral therapy for HIV-infected African children less than 3 years of age. AIDS. 2015; 29(10):1247-59.

13. Pau AK, Moodley NK, Holland DT, Fomundam H, Matchaba GU, Capparelli EV. Instability of lopinavir/ritonavir capsules at ambient temperatures in sub-Saharan Africa: relevance to $\mathrm{WHO}$ antiretroviral guidelines. AIDS. 2005;19(11):1233-4

14. Ren Y, Nuttall JJ, Egbers C, Eley BS, Meyers TM, Smith PJ, Maartens G, Mcllleron HM. Effect of rifampicin on lopinavir pharmacokinetics in HIV-infected children with tuberculosis. J Acquir Immune Defic Syndr. 2008;47(5):566-9.

15. Larru B, Eby J, Lowenthal ED. Antiretroviral treatment in HIV-1 infected pediatric patients: focus on efavirenz. Pediatric Health Med Ther. 2014;5:29-42.

16. Hirt D, Urien S, Olivier M, Peyriere H, Nacro B, Diagbouga S, Zoure E, Rouet $F$, Hien $H$, Msellati $P$, et al. Is the recommended dose of efavirenz optimal in young West African human immunodeficiency virus-infected children? Antimicrob Agents Chemother. 2009;53(10):4407-13.

17. Rouet F, Ekouevi DK, Chaix ML, Burgard M, Inwoley A, Tony TD, Danel C, Anglaret $X$, Leroy $V$, Msellati $P$, et al. Transfer and evaluation of an automated, low-cost real-time reverse transcription-PCR test for diagnosis and monitoring of human immunodeficiency virus type 1 infection in a West African resourcelimited setting. J Clin Microbiol. 2005;43(6):2709-17.

18. Piaggio G, Elbourne DR, Pocock SJ, Evans SJ, Altman DG, Group C. Reporting of noninferiority and equivalence randomized trials: extension of the CONSORT 2010 statement. JAMA. 2012;308(24):2594-604.

19. Jones B, Jarvis $P$, Lewis JA, Ebbutt AF. Trials to assess equivalence: the importance of rigorous methods. BMJ. 1996;313(7048):36-9.

20. Dahourou DL, Amorissani-Folquet M, Coulibaly M, Avit-Edi D, Meda N, Timite-Konan M, Arendt V, Ye D, Amani-Bosse C, Salamon R, et al. Missed opportunities of inclusion in a cohort of HIV-infected children to initiate antiretroviral treatment before the age of two in West Africa, 2011 to 2013. J Int AIDS Soc. 2016;19(1):20601.

21. Amani Bosse C, Dahourou D, Malateste K, M A-F, Coulibaly M, Dattez S, Emieme A, Barry M, Rouzioux C, N'Gbeche M-S, et al. Virological response and resistances over 12 months among HIV-infected children less than 2 years receiving first-line lopinavir /ritonavir-based antiretroviral therapy in Cote d'Ivoire and Burkina Faso: the MONOD ANRS 12206 cohort. J Int AIDS Soc. 2017; in press.

22. Coovadia A, Abrams EJ, Stehlau R, Meyers T, Martens L, Sherman G, Hunt G, Hu CC, Tsai WY, Morris L, et al. Reuse of nevirapine in exposed HIV-infected children after protease inhibitor-based viral suppression: a randomized controlled trial. JAMA. 2010;304(10):1082-90.

23. Coovadia A, Abrams EJ, Strehlau R, Shiau S, Pinillos F, Martens L, Patel F, Hunt G, Tsai WY, Kuhn L. Efavirenz-based antiretroviral therapy among nevirapine-exposed HIV-infected children in South Africa: a randomized clinical trial. JAMA. 2015;314(17):1808-17.

24. Van de Wijer $L$, Schellekens AF, Burger DM, Homberg JR, de Mast $Q$, van der Ven AJ. Rethinking the risk-benefit ratio of efavirenz in HIV-infected children. Lancet Infect Dis. 2016;16(5):e76-81.

25. Arrive E, Newell ML, Ekouevi DK, Chaix ML, Thiebaut R, Masquelier B, Leroy $V$, Perre PV, Rouzioux C, Dabis F. Prevalence of resistance to nevirapine in mothers and children after single-dose exposure to prevent vertical transmission of HIV-1: a meta-analysis. Int J Epidemiol. 2007;36(5):1009-21. 
26. Fogel J, Li Q, Taha TE, Hoover DR, Kumwenda NI, Mofenson LM, Kumwenda JJ, Fowler MG, Thigpen MC, Eshleman SH. Initiation of antiretroviral treatment in women after delivery can induce multiclass drug resistance in breastfeeding HIV-infected infants. Clin Infect Dis. 2011;52(8):1069-76.

27. Zeh C, Weidle PJ, Nafisa L, Lwamba HM, Okonji J, Anyango E, Bondo P, Masaba $\mathrm{R}$, Fowler MG, Nkengasong JN, et al. HIV-1 drug resistance emergence among breastfeeding infants born to HIV-infected mothers during a single-arm trial of triple-antiretroviral prophylaxis for prevention of mother-to-child transmission: a secondary analysis. PLoS Med. 2011;8(3):e1000430.

28. Babiker A, Castro nee Green H, Compagnucci A, Fiscus S, Giaquinto C, Gibb DM, Harper L, Harrison L, Hughes M, McKinney R, et al. First-line antiretroviral therapy with a protease inhibitor versus non-nucleoside reverse transcriptase inhibitor and switch at higher versus low viral load in HIV-infected children: an open-label, randomised phase 2/3 trial. Lancet Infect Dis. 2011;11(4):273-83.

29. Coulibaly M, Meda N, Yonaba C, Ouedraogo S, Congo M, Barry M, Thio E, Siribie I, Koueta F, Ye D, et al. Missed opportunities for early access to care of HIV-infected infants in Burkina Faso. PLoS One. 2014;9(10):e111240.

30. Avit D, Folquet-Amorissani M, Amani-Bosse C, Eliam-Kouakou J, MeaAssande VT, Aka A, Ahoba I, Ekouévi D, Timite Konan M, Leroy V, et al. Access to early infant diagnosis and antiretroviral therapy in Abidjan, Côte d'Ivoire, 2011-2013. In: 21st Conference on Retroviruses and Opportunistic Infections (CROI 2014), 3-6 March 2014, Boston, MA. San Francisco, CA: CROI Foundation/IAS-USA; 2014. Poster 877.

31. Penazzato M, Revill P, Prendergast AJ, Collins IJ, Walker S, Elyanu PJ, Sculpher M, Gibb DM. Early infant diagnosis of HIV infection in low-income and middleincome countries: does one size fit all? Lancet Infect Dis. 2014;14(7):650-5.

32. Ciaranello AL, Park J, Ramirez-Avila L, Freedberg KA, Walensky RP, Leroy V. Early infant HIV-1 diagnosis programs in resource-limited settings: opportunities for improved outcomes and more cost-effective interventions. BMC Med. 2011;9:59.

33. Ndondoki C, Brou H, Timite Konan M, Oga M, Amani Bosse C, Menan H, Ekouévi D, Leroy V. Universal HIV screening at postnatal points of care: which public health approach for early infant diagnosis in Africa? The Côte d'Ivoire study case. PLoS One. 2013;8(8):e67996.

34. Musoke P, Szubert AJ, Musiime V, Nathoo K, Nahirya-Ntege P, Mutasa K, Williams DE, Prendergast AJ, Spyer M, Walker AS, et al. Single-dose nevirapine exposure does not affect response to antiretroviral therapy in HIV-infected African children aged below 3 years. AIDS. 2015;29(13):1623-32.

35. Kekitiinwa A, Musiime V, Thomason MJ, Mirembe G, Lallemant M, Nakalanzi S, Baptiste D, Walker AS, Gibb DM, Judd A. Acceptability of lopinavir/r pellets (minitabs), tablets and syrups in HIV-infected children. Antivir Ther. 2016;21(7):579-85.

36. Dehority W, Abadi J, Wiznia A, Viani RM. Use of integrase inhibitors in HIV-infected children and adolescents. Drugs. 2015:75(13):1483-97.

\section{Submit your next manuscript to BioMed Central and we will help you at every step:}

- We accept pre-submission inquiries

- Our selector tool helps you to find the most relevant journal

- We provide round the clock customer support

- Convenient online submission

- Thorough peer review

- Inclusion in PubMed and all major indexing services

- Maximum visibility for your research

Submit your manuscript at www.biomedcentral.com/submit 